\title{
Influence of handling methods on fecal NIRS evaluations
}

\author{
ROBERT A. PEARCE, ROBERT K. LYONS, AND JERRY W. STUTH
}

\begin{abstract}
Authors are currently graduate student, visiting assistant professor, and professor Department of Rangeland Ecology and Management, Texas A\&M University, College Station 77843.
\end{abstract}

\begin{abstract}
Experiments were conducted to investigate efficiency in analysis of fecal samples by near infrared reflectance spectroscopy (NIRS) to predict cattle forage diet quality. Stability of fecal samples during shipping and methods of reducing analysis time were evaluated. In experiments with actual and simulated shipping, no difference was found between predictions from samples shipped fresh or frozen, allowing analysis time to be reduced by 1 day. Drying procedures were developed which allowed sample analysis 24 hours after arrival in the lab for an additional reduction of 1 day in analysis time. Minimal effects on NIRS predictions were observed for simulated shipping delays up to 12 days for crude protein and 14 days for digestible organic matter.
\end{abstract}

Key Words: near infrared reflectance spectroscopy, cattle, nutrition, fecal matter, crude protein, digestible organic matter

Potential for fecal near infrared reflectance spectroscopy (NIRS) prediction of herbivore forage diet quality has been demonstrated (Brooks et al. 1984, Coleman et al. 1989, Stuth et al. 1989, Lyons and Stuth 1992). Results obtained from NIRS analysis of fecal material have many applications for commercial livestock producers such as determining the nutritional balance for free-roaming herds. Information received from NIRS fecal analysis could be used to determine when to initiate or discontinue livestock supplemental feeding programs. Feasibility of fecal NIRS analysis for use in range livestock management will depend on the promptness with which results are available for use in management decisions.

\footnotetext{
This manuscript was published with the approval of the director, Texas Agricultural Experiment Station, Texas A\&M University as TA-30324.

Manuscript accepted 19 Sept. 1992
}

Therefore, factors such as shipping time and sample drying time become important. It also is imperative to know if delays during shipping affect diet quality predictions.

The purpose of this paper is to provide information concerning sample shipping and drying which could facilitate commercialization of NIRS fecal analysis technology. Experiments were conducted to (1) determine if samples could be mailed fresh instead of frozen to reduce turnaround time by at least I day; (2) determine if reduced sample size and modified drying procedures would allow samples to be analyzed 24 hours after arrival in the lab; and (3) determine if delays in shipping affect predictions of forage diet quality.

\section{Methods}

A shipping experiment was conducted in which fecal samples were collected from cattle on the Yribarren Ranch in Inyo County, Calif. Samples were taken from cattle that grazed in the Owens Valley at elevations of about $1,220 \mathrm{~m}$ from 14 May to $12 \mathrm{July}$, in the Sierra Nevada Mountains at elevations between 2,500 and 3,100 m from 13 July to 7 August, and returned to the Owens Valley 8 August through 18 August 1991. Fecal collections were made at 2-week intervals from 3 separate sites within the location currently being grazed. Samples from 10 cows within each site were composited and thoroughly mixed. Composite samples were divided and placed in polyethylene zipper-seal bags with half shipped fresh and half frozen-both with freeze packs in styrofoam mailers by 2-day mail service to the Range Nutrition Lab at Texas A\&M University. Thus, 15 fresh and 15 frozen samples were taken from the Owens Valley and 6 fresh and 6 frozen samples were from the Sierra Nevada Mountains. 
Species composition of the Owens Valley meadows is primarily sedges (Carex spp.), saltgrass (Distichlis spicata var. stricta (L.) Greene.), bird's-foot trefoil (Lotus corniculatus Waldst. \& Kit. ex. Willd.), baltic rush (Juncus balticus Willd.), and creeping wildrye (Leymus triticoides Buckl.) (Novak, unpublished data 1990).

Species composition of the mountain meadows is primarily sedges (Carex spp.), mat muhly (Muhlenbergia richardsonis (Trin.) Rydb.), rushes (Juncus spp.), and lupine (Lupinus pratensis Heller.). Species composition in the surrounding shrub/grass community consists of predominately sagebrush (Artemisia spp.), bitterbrush (Purshia spp.), mountain mahogany (Cercocarpus spp.), ricegrass (Oryzopsis spp.), and needle-and-thread grass (Stipa comata Trin. \& Rupr.), (Novak, and USDA FS unpublished data 1990).

Twenty-one frozen and 21 fresh samples were analyzed in this experiment. Unless indicated, samples in all experiments reported in this paper were dried for 48 hours in a forced-air oven at $60^{\circ} \mathrm{C}$ and then ground in Udy Cyclone mill to pass through a $1-\mathrm{mm}$ screen. Sample moisture was stablized by forced-air oven drying overnight at $60^{\circ} \mathrm{C}$ and samples cooled 1 hour in a desiccator prior to NIRS analysis (Lyons and Stuth 1991). Samples in this experiment were scanned in duplicate, and forage diet crude protein (CP) and in vivo corrected digestible organic matter (DOM) were predicted with fecal NIRS equations (Lyons and Stuth 1992). Data were analyzed in a randomized complete block with sub-sampling using samples as blocks and sample $\times$ replication as the error term to test treatment effects.

Effects of shipping samples fresh and frozen were also simulated using 28 individual fecal samples collected over a 4-week period from cows grazing native pastures near College Station, Tex. Equal portions of each sample were placed fresh with a freeze-pack in a styrofoam mailer or frozen and then placed with a freeze-pack in a mailer to simulate 2-day delivery. Samples were then processed for NIRS analysis. Data were analyzed in a randomized complete block design with samples as blocks.

Sample stability during delayed shipping was tested using composited feces from 8 cows grazing native pastures near College Station, Tex. One hundred ninety-six, 50-cc subsamples of a fresh homogeneous fecal mixture were placed in zipper-seal, plastic bags and then placed with freeze-packs in a styrofoam mailer stored at room temperature. Samples were removed from mailers at 2-day intervals to create 7 treatments consisting of day 2 through day 14 . Each treatment was present in each of 14 mailers and each treatment was duplicated within each mailer. When removed from mailers, samples were processed as previously indicated for NIRS analysis. Data were analyzed in a randomized complete block using mailers as blocks. Protected least significant differences (LSD) was used for mean separation.

Potential for reducing sample drying time was tested using 45 individual fecal samples collected over a 6-week period at College Station, Tex. Sample size was reduced to $100-\mathrm{cc}$ and samples placed in ovens at $60^{\circ} \mathrm{C}$ until dry enough to grind (about 24 hours). After grinding, each sample was divided into 2 equal portions, placed into paper coin envelopes, and returned to the forced-air ovens. One portion was removed from the ovens after 1 hour, cooled in a desiccator, and scanned by NIRS. The second portion remained in ovens overnight before scanning. Data were analyzed in a randomized complete block using samples as blocks.

\section{Results and Discussion}

No differences were found in NIRS predictions for $C P(P=0.24)$ or DOM (P $=0.47)$ between samples sent fresh or frozen in the actual shipping experiment (Table 1 ). In addition, no differences in NIRS predictions were found in the simulated shipping experiment (Table 1) for CP $(P=0.25)$ or DOM $(P=0.14)$. Because
Table 1. Comparison of NIRS predicted percent diet crude protein (CP) and percent in vivo corrected dizestible organic matter (DOM) from fresh and frozen fecal samples for actual and simulated shipping studies.

\begin{tabular}{lccc}
\hline \hline Treatment & Mean & $\mathrm{SE}^{\mathrm{I}}$ & Probability $^{2}$ \\
\hline Actual Shipping ( $=42)$ & $(\%)$ & & \\
Fresh CP & 11.6 & 0.24 & 0.24 \\
Frozen CP & 11.7 & 0.26 & \\
Fresh DOM & 58.4 & 0.34 & 0.47 \\
Frozen DOM & 58.5 & 0.36 & \\
Simulated Shipping ( $=28)$ & & & \\
Frozen CP & 12.3 & 0.24 & 0.25 \\
Frozen CP & 12.2 & 0.25 & \\
Fresh DOM & 61.8 & 0.16 & 0.14 \\
Frozen DOM & 61.6 & 0.14 & \\
\hline
\end{tabular}

ISE = Standard Error

2Probability that mean predictions from fresh and frozen treatments are significantly different.

freezing usually delays shipping by at least 1 day and can delay drying if samples arrive partially frozen, sending fresh samples can reduce analysis time, providing livestock producers with more timely management information.

Sample stability is a concern when fresh or frozen feces are mailed because transit times may be variable. In a sample stability study, both CP and DOM predictions were affected $(P<.01)$ by simulated delays in shipping (Table 2). Generally, CP increased over the 14-day period, while the DOM showed a variable response (Table 2). Although statistically significant these differences were

Table 2. Sample stability comparisons for NIRS predicted percent crude protein (CP) and percent in vivo corrected digestible organic matter (DOM) for 2 days through 14 days.

\begin{tabular}{ccc}
\hline \hline Day & Mean & $\mathrm{SE}^{1}$ \\
\hline $\mathrm{CP}(\mathrm{n}=192)$ & $(\%)$ & \\
2 & $9.2^{\mathrm{a}}$ & .07 \\
4 & $9.4^{\mathrm{a}}$ & .09 \\
6 & $9.7^{\mathrm{b}}$ & .08 \\
8 & $9.7^{\mathrm{b}}$ & .06 \\
10 & $9.5^{\mathrm{a}, \mathrm{b}}$ & .11 \\
12 & $9.7^{\mathrm{b}}$ & .10 \\
14 & $10.1^{\mathrm{c}}$ & .09 \\
DOM (n=192) & & \\
2 & $59.6^{\mathrm{a}}$ & .05 \\
4 & $59.8^{\mathrm{b}}$ & .06 \\
6 & $59.7^{\mathrm{a}, \mathrm{b}}$ & .05 \\
8 & $59.3^{\mathrm{c}}$ & .06 \\
10 & $59.7^{\mathrm{a}, \mathrm{b}}$ & .05 \\
12 & $59.6^{\mathrm{a}}$ & .05 \\
14 & $59.1^{\mathrm{c}}$ & .05 \\
\hline
\end{tabular}

ISE = Standard error

Means in a column with the same letter are not significantly different $(P<0.01)$.

of questionable practical importance. For example, CP changed less than 1 percentage point with the maximum mean predicted value occurring on day 14 (Table 2). Changes in DOM were also less than 1 percentage point (Table 2), remaining in the $59 \%$ range during the 2 -week study period. These results appear to indicate that substantial shipping delays would have minimal effects on NIRS predictions of CP and DOM, particularly if the samples were not exposed to excessively high temperatures.

No differences were found for predictions of $C P(P=0.32)$ or $\operatorname{DOM}(\mathrm{P}=0.17)$ between 1 -hour or overnight post-grinding drying (Table 3). Based on these results, we suggest the technique of reducing sample size and using l-hour post-grinding drying to stabilize sample moisture would allow samples to be analyzed 
Table 3. Comparision of NIRS predicted percent diet crude protein (CP) and percent in vivo corrected digestible organic matter (DOM) for samples dried 1 hour (1HR) post-grinding vs. samples dried overnight post grinding. Both treatments were dried 24 hours at $60^{\circ} \mathrm{C}$ and ground to $1 \mathrm{~mm}$.

\begin{tabular}{lccc}
\hline \hline Treatment & Mean & SE $^{1}$ & Probability $^{2}$ \\
\hline CP $(\mathrm{n}=45)$ & $(\%)$ & & \\
1 Hour & 9.6 & 0.29 & 0.32 \\
Overnight & 9.4 & 0.25 & \\
DOM $(\mathrm{n}=45)$ & & & \\
1 Hour & 59.0 & 0.35 & 0.17 \\
Overnight & 59.1 & 0.32 & \\
\hline
\end{tabular}

ISE $=$ Standard Error.

${ }^{2}$ Probability that the mean predictions for 1 hour and overnight treatments are significantly different.

about 24 hours after arrival in the lab. This procedure could reduce analysis time by an additional day.

NIRS technology can help increase our understanding of the nutritior $l$ et twe of $\mathrm{fr}$ or ming ungu' toe in a tim sly $\mathrm{m}$ nr ${ }^{\circ} \mathrm{r}$
Results from the actual shipping study indicate sampling in remote locations is feasible. It is also evident that samples can be stored at cool temperatures for extended periods, permitting researchers to accumulate samples for up to 7-10 days prior to shipping or processing. Properly equipped laboratories can process samples for analysis the next-day after receipt. This study demonstrates the wide adaptability and timeliness of NIRS fecalanalysis for prediction of dietary quality.

\section{Literature Cited}

Brooks III, J., M. Anderson, and P.J. Urness. 1984. Infrared reflectance analysis of forage quality for elk. J. Wildl. Manage. 48:254-258.

Coleman, S.W., J.W. Holloway, and J.W. Stuth. 1989. Monitoring the nutrition of grazing cattle with near-infrared analysis of feces. XVI Internat. Grassl. Congr. 16:881-882. Nice, France.

Lyons, R.K., and J.W. Stuth. 1991. Procedures for processing cattle fecal samples for NRIS analysis. Anim. Feed Sci. Tech. 35:21-36.

Lyons, R.K., and J.W. Stuth. 1992. Fecal NIRS equations for predicting diet quality of free-ranging cattle. J. Range Manage. 45:238-244.

Stuth, J.W., E.D. Kapes, and R.K. Lyons. 1989. Use of near infrared spectroscopy to assess nutritional status of cattle diets on rangeland. XVI Internat. Grassl. Congr. 16:889-890. Nice, France. 